SLE physiopathology has provided to analytic and immunological criteria in the subsequent classification criteria.

Disclosure of Interests: David Lobo Prat: None declared, Berta Magallares: None declared, Ivan Castellví Consultant of: Boehringer Ingelheim, Actelion, Kern Pharma, Speakers bureau: Boehringer Ingelheim, Actelion, Bristol-Myers Squibb, Roche, HyeSang Park: None declared, Patricia Moya: None declared, Ignasi Gich: None declared, Ana Laiz: None declared, Cesar Díaz-Torné: None declared, Ana Milena Millán Arciniegas: None declared, Susana P. Fernandez-Sanchez: None declared, Hector Corominas: None declared

DOI: 10.1136/annrheumdis-2020-eular.6190

\section{SAT0218 $\quad$ SINGLE NUCLEOTIDE POLYMORPHISMS LOCATED IN REGULATORY REGIONS OF GENES INVOLVED IN SYSTEMIC INFLAMMATION (MAMDC1, ITGAM, AND CRP) CORRELATION WITH THE CLINICAL PICTURE OF DISEASE AND ACTIVITY PARAMETERS IN SYSTEMIC LUPUS ERYTHEMATOSUS}

A. Majdan ${ }^{1}$, R. Mlak ${ }^{1}$, M. Mazurek ${ }^{1}$, D. Pigon ${ }^{1}$, M. Majdan ${ }^{1,2}$, T. Malecka Massalska ${ }^{1} .{ }^{1}$ Medical University of Lublin, Dept of Human Physiology, Lublin, Poland; ${ }^{2}$ Medical University of Lublin, Dept of Rheumatology and Connective Tissue Diseases, Lublin, Poland

Background: The exact pathogenesis of systemic lupus erythematosus (SLE) is poorly understood. It is an autoimmune disease that leads to a chronic inflammatory process involving numerous tissues and organs (skin, kidneys, joints, central nervous system, cardiovascular, respiratory, digestive and hematopoietic systems). However, despite the advancement of SLE molecular biology and the wide availability of tests and diagnostic tools, the knowledge about factors predicting the clinical disease activity as well as related changes in the laboratory results is insufficient.

Objectives: The goal of the study was to assess the relationship between selected single nucleotide polymorphisms (SNPs) and the clinical picture of disease and some activity parameters in patients with SLE.

Methods: We conducted a study of adult patients with SLE diagnosed and treated in the Rheumatology Department of Medical University of Lublin between 2016-2019. We enrolled 80 patients with SLE (71 women, 9 men), with the median (range) age 36 (19-72) and disease duration 6 (1-37) years. To objectively assess disease activity, standardized SLE activity scale - SLEDAI (Systemic Lupus Erythematosus Disease Activity Index) was used. Using the Real-Time PCR method and specific TaqMan probes SNPs of 3 genes: MAMDC1 (rs910875; c. $-1687 \mathrm{G}>\mathrm{C}$ ), CRP (rs3091244; c.-390C> A), and ITGAM (rs7193943; c.-323G> A) were analyzed and then their relationship with specific clinical picture of disease, activity and laboratory results were assessed.

Results: Carriers of the CC genotype compared to the remaining polymorphic variants (CG and GG) of the MAMDC1 gene had an approximately 4-fold higher risk of skin disease compared to other clinical pictures of disease (renal, articular, neuro-psychiatric, hematological) (OR $=4.04 ; p=0.0110)$ ). Carriers of this genotype also had a higher risk of hematuria $(O R=4.57 ; p=0.0082$ ), sterile leukocyturia $(O R=53.91 ; p=0.0071)$, the presence of anti-Sm / RNP antinuclear antibodies $(O R=4.15, p=0.0074)$, reduced values of the $C 3$ complement component $(\mathrm{OR}=6.11 ; p=0.0071)$ and the need for oral glucocorticosteroids $(O R=7.01 ; p=0.0028)$. In addition, significantly higher values of SLEDAI disease activity scale were observed in carriers of the CC genotype of the MAMDC1 gene (medians: 6 vs $4 ; p=0.0220$ ). Moreover, we observed a trend towards a higher risk of hepatomegaly in GG genotype carriers of the ITGAM gene (OR=18.50; $\mathrm{p}=0.0525)$. In addition, the AA genotype of the CRP gene was associated with a higher risk of proteinuria (OR $=84 ; p<0.0001$ ), Anti-SSA / Ro autoantibodies (OR = 3.29; $p=0.0484$ ), and $\mathrm{aCL} \operatorname{lgM}(\mathrm{OR}=$ $3.42 ; p=0.0332$ ) occurrence. Carriers of $A A$ genotype of the above gene were also at higher risk of earlier occurrence of first disease symptoms as well as disease diagnosis at a younger age (respectively: 24 vs 31 years; $p=0.0225$, 23 vs 29 years; 0.0442).

Conclusion: The results suggest the relationship between SNPs in genes involved in systemic inflammation (MAMDC1, ITGAM, CRP) and disease activity as well as the occurrence of some specific clinical pictures of disease in patients with SLE.The genetic dispositions described above may serve as attractive markers in SLE, potentially useful in clinical practice.

Disclosure of Interests: Aleksandra Majdan: None declared, Radosław Mlak: None declared, Marcin Mazurek: None declared, Dominika Pigon: None declared, Maria Majdan Consultant of: Roche, Amgen, Speakers bureau: Roche, Amgen, Teresa Malecka Massalska: None declared

DOI: 10.1136/annrheumdis-2020-eular.3742

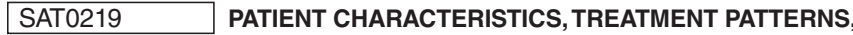 AND RESOURCE UTILIZATION OF SJOGREN'S SYNDROME PATIENTS IN A LARGE US HEALTH NETWORK}

${ }_{\text {P. J. Mease }}{ }^{1}$, J. Zhuo ${ }^{2}$, R. Weerasinghe ${ }^{3}$, Q. Xia ${ }^{2}$, C. Samal $^{4}$, N. Sharma ${ }^{4}$. ${ }^{1}$ Swedish Medical Center/Providence St. Joseph Health, Seattle, United States of America; ${ }^{2}$ Bristol-Myers Squibb, Lawrenceville, United States of America; ${ }^{3}$ Providence St. Joseph Health, Renton, United States of America; ${ }^{4} \mathrm{Mu}$-Sigma, Bangalore, India

Background: Sjogren's syndrome (SS) is a chronic progressive autoimmune dis order which occurs as primary (pSS) or secondary SS (sSS). With no approved disease modifying therapy, there is limited information on the treatment patterns and resource utilization among these patients (pts).

Objectives: To describe pts characteristics, treatment patterns and healthcare resource utilization (HCRU) using electronic health records (EHR) of pts with pSS and sSS treated at the Providence St. Josephs Health system (PSJH).

Methods: Pts $\geq 18$ years of age with at least one clinical encounter with ICD9-CM or ICD-10-CM diagnosis of SS, between Jan 2013 and Mar 2019 were included. Date of first encounter with SS diagnosis (index date) was used to assess pts demographics. Pt baseline comorbidities were evaluated during the 24 months pre-index period. Treatment patterns and HCRU were assessed during the 12 months post-index follow-up. Descriptive statistics were used to

Table 1. Baseline Demographic and Clinical Pts Characteristics

SS Pts $(n=9,108)$

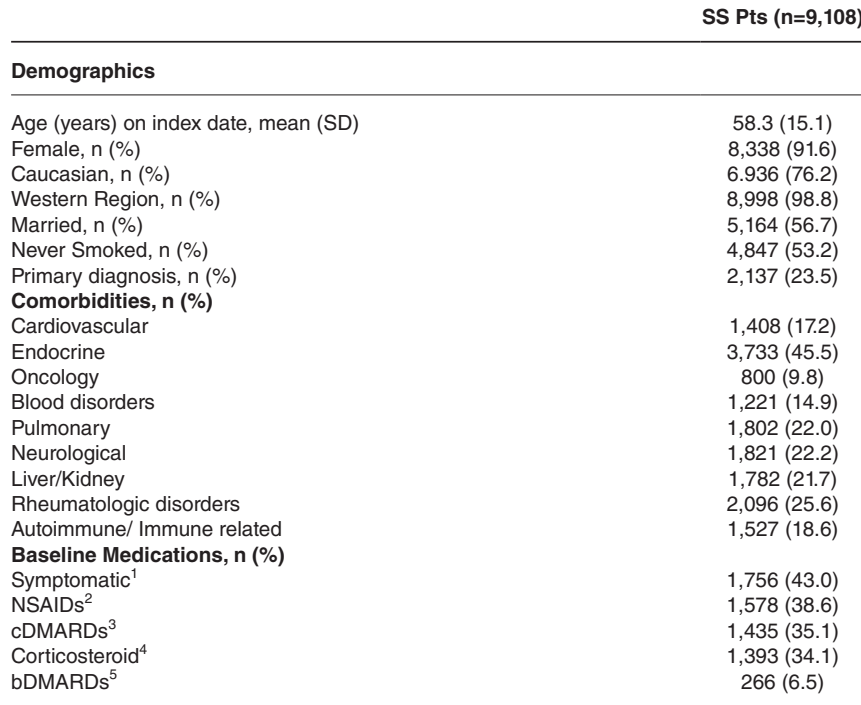

${ }^{1}$ cevimeline, pilocarpine hydrochloride, ophthalmic insert etc; ${ }^{2}$ aspirin, ibuprofen, naproxen ${ }^{3}$ methotrexate, hydroxychloroquine, sulfasalazine, leflunomide, myophenolate mofetil, azathioprine: ${ }^{4}$ prednisone: ${ }^{5}$ sarilumab, belimumab, ustekinumab, infliximab, adalimumab, certolizumab pegol, golimumab, etanercept, abatacept, tocilizumab, rituximab, tofacitinib, baricitinib

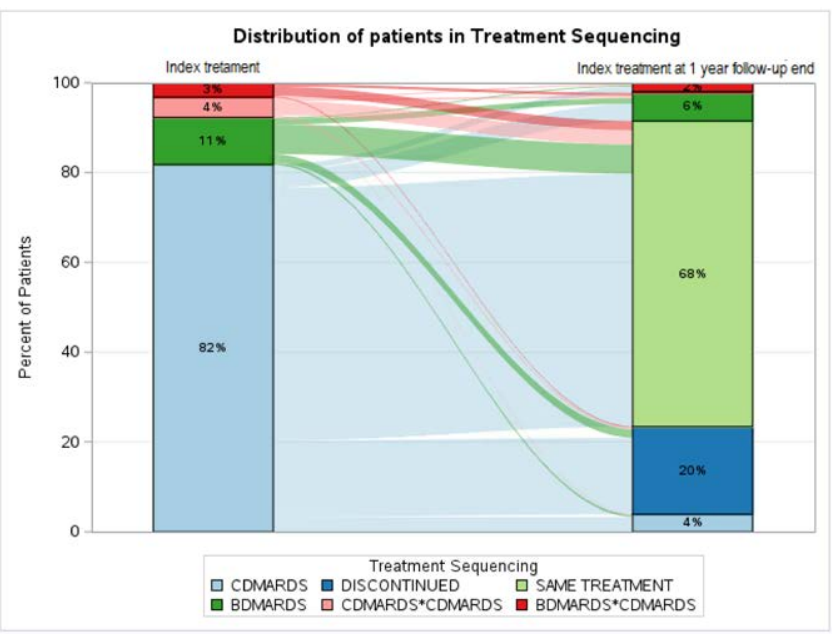

Figure 1. HCRU for pSS and sSS Pts 


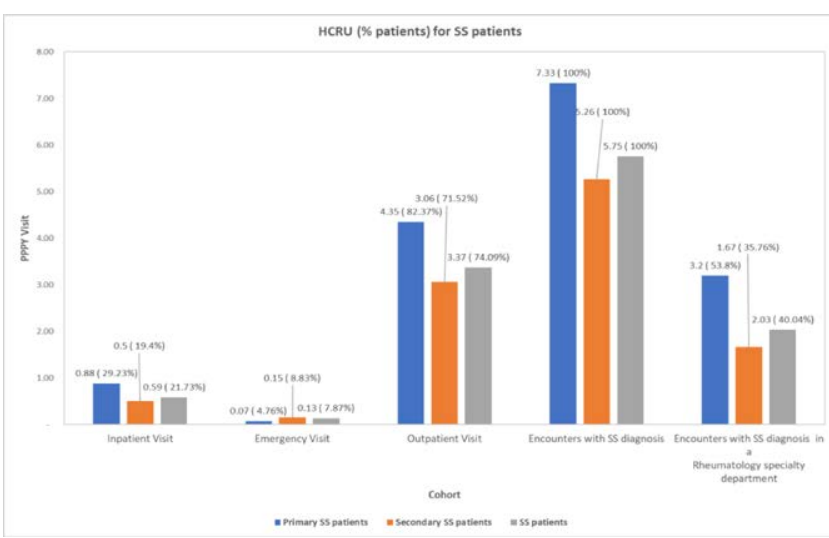

Figure 2. Treatment Sequencing for pSS and sSS PtsNote:Discontinued: pts who discontinued and didn't advance to any therapy; same treatment: pts continued on index treatment till we have information.

describe pts' demographic and clinical characteristics, and medications use in the baseline and follow up.

Results: Study cohort included 9,108 SS pts of which $76.5 \%$ had sSS diagnosis on index date. Majority of SS pts were women, Caucasian, with mean age of 58.3 yrs, and from western states in the US (Table 1). Endocrine conditions including hypo- and hyperthyroidism, and diabetes was the most common (45.5\%) comorbidity at baseline, followed by rheumatologic disorders (25.6\%) and neurological conditions (22.2\%). Among patients with treatment information (4088, 44.88\%), $42.95 \%$ were using symptomatic treatments for dry eye and mouth at baseline (Table 1). In the follow-up, SS pts had average 5.8 healthcare visits per patient per year (PPPY), including 0.6 inpatient and 3.4 outpatient visit respectively. About $40 \%$ of the SS pts (53.8\% pSS and $35.8 \%$ sSS) were diagnosed by rheumatologists. Majority of the SS pts initiated treatment with cDMARDs (82\%) and remained on the same treatment during 1 year follow-up (Fig 2).

Conclusion: Observation of higher comorbidities suggests substantial burden of SS pts on healthcare system, with majority of pts being diagnosed outside of rheumatology offices.

Acknowledgments: : We acknowledge the contributions of Manasi Suryavanshi towards drafting and reviewing the abstract.

Disclosure of Interests: Philip J Mease Grant/research support from: Abbott, Amgen, Biogen Idec, BMS, Celgene Corporation, Eli Lilly, Novartis, Pfizer, Sun Pharmaceutical, UCB - grant/research support, Consultant of: Abbott, Amgen, Biogen Idec, BMS, Celgene Corporation, Eli Lilly, Novartis, Pfizer, Sun Pharmaceutical, UCB - consultant, Speakers bureau: Abbott, Amgen, Biogen Idec, BMS, Eli Lilly, Genentech, Janssen, Pfizer, UCB - speakers bureau, Joe Zhuo Shareholder of: Bristol-Myers Squibb, Employee of: Bristol-Myers Squibb, Roshanthi Weerasinghe Grant/research support from:., Qian Xia Shareholder of: I own shares of Bristol-Myers Squibb Company, Employee of: I am a paid employee of Bristol-Myers Squibb Company, Chidananda Samal Consultant of: I work as a consultant for Bristol-Myers Squibb Company, Niyati Sharma Consultant of: I work as a consultant for Bristol-Myers Squibb Company

DOI: 10.1136/annrheumdis-2020-eular.4187

\begin{tabular}{|l|l|}
\hline SAT0220 & BIOLOGICAL PREDICTORS OF ECHOGRAPHIC \\
SALIVARY GLAND INVOLVEMENT SEVERITY IN \\
PATIENTS WITH SJÖGREN'S SYNDROME
\end{tabular}

A. Mihai', D. Mardale', D. Opris-Belinski², R. Ionescu'², C. Jurcut'. ' '“Dr. Carol Davila"Central Emergency University Military Hospital, Bucharest, Romania; 2 "Sf. Maria"Clinical Hospital,"Carol Davila” University of Medicine and Pharmacy, Bucharest, Romania

Background: Echographic evaluation of salivary gland increasingly became a routine imaging modality in patients with Sjogren's syndrome (SS). However, predictive parameters associated with the severity of echographic features are still incomplete evaluated.

Objectives: The aim of this study was to evaluate the predictors for severe echographic involvement in patients with SS followed in a tertiary center.

Methods: We included 63 patients with SS (mean age: $52.3 \pm 11.9 ; 59$ female). The complete laboratory workup, clinical manifestations and treatment were reviewed and the EULAR Sjögren's syndrome disease activity index (ESSDAI) was calculated for each patients. We performed the standard echographic evaluation of salivary gland in all patients and used a 4 grade system for severity staging.

Results: The distribution of echographic grade was: no any echographic features -4 pts $(6.3 \%)$; grade $1-24$ pts $(38.1 \%)$; grade $2-20$ pts $(31.7 \%)$; grade 3 - 10 pts (15.9\%); grade $4-5$ pts (7.9\%). The ESSDAI and the hydroxichloroquine use were similar in these subgroups. We didn't find differences regarding CRP and fibrinogen and echographic features. The age of the patients, the anti-SSA and anti-SSB, ESR, total protein, IgA, IgG and rheumatoid factor levels were significantly higher and lymphocyte count was lower in patients with echographic severity above grade 2 when compared with patients with no or mild echographic features. However, using ANOVA test and post-hoc analysis, the only parameters associated with the severity of echographic features were high ESR (53 vs 17 in grade 4 vs $1, p=0.02$ ), $\operatorname{lgA}$ (363 vs 190 in grade 4 vs $1, p=0.004)$ and $\lg$ (1985 vs $1191 \mathrm{U} / \mathrm{l}$ in grade 4 vs $1, p=0.001$ ) levels.

Conclusion: Parameters linked to polyclonal hypergammaglobulinemia (IgA and IgG levels; and ESR) seem to be linked to the severity of echographic appearance of salivary gland in patients with SS. Further studies are needed in order to better characterize this link.

Disclosure of Interests: Ancuta MIHAI: None declared, DENISE MARDALE None declared, Daniela Opris-Belinski Speakers bureau: as declared, Ruxandra lonescu Consultant of: Consulting fees from Abbvie, Eli-Lilly, Novartis, Pfizer, Roche, Sandoz, Speakers bureau: Consulting and speaker fees from Abbvie, EliLilly, Novartis, Pfizer, Roche, Sandoz, Ciprian Jurcut: None declared DOI: 10.1136/annrheumdis-2020-eular.2292

\begin{tabular}{|l|l|}
\hline SAT0221 & FACTORS AFFECTING MORTALITY OF SYSTEMIC \\
& LUPUS ERYTHEMATOSUS PATIENTS IN SPAIN IN \\
& THE 21ST CENTURY: DATA FROM THE RELESSER \\
& REGISTRY
\end{tabular}

C. Moriano $^{1}$, J. Calvo ${ }^{2}$, I. Rua-Figueroa ${ }^{3}$, E. Diez Alvarez ${ }^{1}$, C. Bermúdez ${ }^{4}$ F. J. López-Longo ${ }^{5}$, M. Galindo-Izquierdo ${ }^{6}$, A. Olive ${ }^{7}$, E. Tomero Muriel ${ }^{8}$, A. Fernandez-Nebro ${ }^{9}$, M. Freire González ${ }^{10}$, O. Fernández-Berrizbeitia ${ }^{11}$ A. Pérez Gómez ${ }^{12}$, E. Uriarte Isacelaya ${ }^{13}$, C. Marras Fernandez $\mathrm{Cid}^{14}, \mathrm{C}$. A. Montilla-Morales ${ }^{15}$, G. Santos Soler ${ }^{16}$, R. Blanco ${ }^{17}$, M. Rodíguez-Gómez ${ }^{18}$, P. Vela-Casasempere ${ }^{19}$, A. Boteanu ${ }^{20}$, J. Narváez $^{21}$, V. Martinez Taboada ${ }^{17}$, B. Hernández-Cruz ${ }^{22}$, J. L. Andreu ${ }^{23}$, J. A. Hernandez Beriain ${ }^{24}$, L. Expósito ${ }^{25}$, R. Menor-Almagro ${ }^{26}$, M. Ibañez Barceló ${ }^{27}$, I. Castellví ${ }^{28}$, C. Galisteo ${ }^{29}$, E. Raya ${ }^{30}$, V. Quevedo Vila ${ }^{31}$, T. Vazquez Rodriguez ${ }^{32}$, J. Ibañez ${ }^{33}$, J. M. Pego-Reigosa ${ }^{34}$. ${ }^{1}$ H León, León, Spain; ${ }^{2}$ H Araba, Vitoria, Spain; ${ }^{3}$ H Negrín, Las Palmas Gran Canaria, Spain; ${ }^{4}$ Research Unit Bioaraba, Vitoria, Spain; ${ }^{5} \mathrm{H}$ Gregorio Marañón, Madrid, Spain; ${ }^{6} \mathrm{H} 12$ Octubre, Madrid, Spain; ${ }^{7} \mathrm{H}$ German Trias i Pujol, Badalona, Spain; ${ }^{8} \mathrm{H}$ La Princesa, Madrid, Spain; ${ }^{9} \mathrm{H}$ Carlos Haya, Málaga, Spain; ${ }^{10} \mathrm{H}$ Juan Canalejo, A Coruña, Spain; ${ }^{11} \mathrm{H}$ Basurto, Bilbao, Spain; ${ }^{12} \mathrm{H}$ Príncipe Asturias, Madrid, Spain; ${ }^{13} \mathrm{H}$ Donosti, San Sebastián, Spain; ${ }^{14} \mathrm{H}$ Virgen Arrixaca, Murcia, Spain; ${ }^{15} \mathrm{H}$ Salamanca, Salamanca, Spain; ${ }^{16} \mathrm{H}$ Marina Baixa, Villajoyosa, Spain; ${ }^{17} \mathrm{H}$ Marqués Valdecilla, Santander, Spain; ${ }^{18} \mathrm{H}$ Orense, Orense, Spain; ${ }^{19} \mathrm{HG}$ Alicante, Alicante, Spain; ${ }^{20} \mathrm{H}$ Ramón y Cajal, Madrid, Spain; ${ }^{21} \mathrm{H}$ Bellvitge, Hospitalet, Spain; ${ }^{22} \mathrm{H}$ Virgen Macarena, Sevilla, Spain; ${ }^{23} \mathrm{H}$ Puerta Hierro, Madrid, Spain; ${ }^{24} \mathrm{H}$ Insular, Las Palmas Gran Canaria, Spain; ${ }^{25} \mathrm{H}$ Canarias, Tenerife, Spain; ${ }^{26} \mathrm{H}$ Jerez Frontera, Jerez, Spain; ${ }^{27} \mathrm{H}$ Son Llátzer, Palma de Mallorca, Spain; ${ }^{28} \mathrm{H}$ Santa Creu i San Pau, Barcelona, Spain; ${ }^{29} \mathrm{H}$ Parc Taulí, Sabadell, Spain; ${ }^{30} \mathrm{H}$ San Cecilio, Granada, Spain $;{ }^{31} \mathrm{H}$ Monforte, Monforte, Spain; ${ }^{32}$ H Lugo, Lugo, Spain; ${ }^{33} \mathrm{H}$ Povisa, Vigo, Spain; ${ }^{34} \mathrm{H}$ Meixoeiro, Vigo, Spain

Background: The mortality in Systemic Lupus Erythematosus (SLE) varies largely across different countries most probably due to social, healthcare and ethnic differences.

Objectives: To analyze the causes and identify predictive factors of mortality of SLE in Spain in the present century.

Methods: We performed a cross-sectional and retrospective study analyzing data from the RELESSER cohort (Spanish Registry of Systemic Lupus Erythematosus of the Spanish Society of Rheumatology). We included all patients diagnosed with SLE since the year 2000 and recorded sociodemographic, clinical and serological variables, comorbidities and treatments, as well as indicators of disease activity, damage and severity. The characteristics of the deceased patients were compared with those of the survivors, and variables with clinical significance or statistical significance were grouped into multivariate models to determine which ones were independently associated with the outcome of the disease.

Results: A total of 2004 patients were included, $88.6 \%$ female, the mean age at diagnosis was $38.3( \pm 15.3)$ years, with a mean delay in diagnosis of $28.9( \pm 52.6)$ months. Up to $2.84 \%$ of the individuals had died. The leading cause of death was SLE activity $(n=16)$, followed by infections $(n=14)$, vascular events $(n=7)$ and can$\operatorname{cer}(n=6)$. The mean age of death was $54.68( \pm 20.13)$ years, and neither age, sex nor delay in diagnosis was independently associated with mortality. The presence of nephritis, depression, severe infections, organ damage (SLICC/ACR DI) or disease activity (SLEDAI), as well as the use of cyclophosphamide, rituximab or high doses of corticosteroids, were predictors of mortality in our cohort. Antimalarial treatment and skin manifestations were linked to improved survival.

Conclusion: In the RELESSER cohort, clinical factors, co-morbidities, as well as therapeutic attitudes were associated with a significant increase in mortality in SLE. Interestingly, depression was independently associated to mortality. The activity of the disease and infections continue to be the main causes of death at the beginning of the 21 st century amongst our patients. 